- This model of out-of-hours/emergency dental care provision has the potential to reduce unecessary medical appointments and dental call outs.

- The model has the potential to reduce the number of dental referrals by ensuring that the initial appointment is provided by the most appropriate care provider.

- The provision of an efficient drop-in facility for unregistered patients allows them to access care when they require it.

- The model has the potential to be easily implemented into dental primary care. where access to dental services within surgery hours is readily available.

\title{
Out-of-hours emergency dental services - evaluation of the first year of a pilot project in Fife
}

\author{
G. V. A. Topping ${ }^{1}$
}

\begin{abstract}
The Scottish Executive Health Department approved funding in 2001 for Fife NHS Board to pilot an integrated model of out-ofhours dental services based upon a dental nurse-led triage system during the evenings, weekends and some public holidays. After one year of the pilot project the activity was evaluated by analysing the triage database. Nearly 4,000 calls were received - Fridays and Saturdays were the most popular days to telephone which resulted in nearly half of all callers being referred to an emergency weekend clinic. Thirty-nine percent of callers received advice only or were advised to contact their own dentist during working hours. A further 12\% who were not registered with a dentist $(n=479)$ were offered a next-day appointment with a dentist in their area - around half of these callers subsequently attended for an appointment. Only two out of every 100 callers were deemed to require emergency out-of-hours attention and were referred to oral surgery staff in a local hospital.
\end{abstract}

In order to examine patient satisfaction with the pilot service and dentists' views on the accuracy of the triage algorithm, questionnaires were distributed to 200 patients attending the weekend emergency dental service clinic and the dentists who treated them with response rates of 95\% and $97 \%$ respectively. Patient satisfaction with the triage-line $(n=200)$ and rota practices $(n=173)$ was investigated using postal questionnaires with response rates respectively of $58 \%$ and $41 \%$.

The levels of satisfaction expressed by patients about the weekend service and triage line were especially high - 97\% and 90\% respectively. The level of satisfaction expressed regarding the next day appointment service was somewhat lower at 71\%, however, less than half of those who were sent questionnaires returned them $(n=69$,

1Director of Dental Caries Control Programme/Honorary Consultant in Dental Public Health, Dental Health Services Research Unit, University of Dundee, Dundee DD2 4BF. Correspondence to Dr G. V. A. Topping Email: g.topping@chs.dundee.ac.uk

\section{Refereed Paper}

Received 29.01.03; Accepted 15.04.04

doi: 10.1038/sj.bdj.4812080

๑ British Dental Journal 2005; 198: 193-197
41\%) and less than half of these respondents $(n=28,41 \%)$ commented on their satisfaction with the service. The dentists reported that, in their opinion, the vast majority of the patients $(87 \%, \mathrm{n}=168)$ seen at the weekend service had problems which warranted the urgent appointment they had been given. Nearly half presented with toothache $(n=90)$ while less common complaints included dry socket $(n=15)$, loose crown or bridgework $(n=11)$, broken down teeth $(n=8)$, pericoronitis $(n=3)$, and trauma $(n=5)$.

The pilot model of out-of-hours care was well received by the majority of patients questioned and the dentists' responses suggest that the algorithm has been satisfactory. A 74\% decrease in claims from Fife GDPs for attending patients out-of-hours also suggests that there is a widespread acceptance of the pilot model of care.

This paper also discusses the additional benefits of the project to Fife patients, both registered and unregistered, GDPs and non-dental colleagues involved in the provision of out-of-hours care for individuals with dental problems.

Out-of-hours emergency dental care has been shown to vary significantly across the UK, particularly services for unregistered patients. However, poor accessibility and availability of such services has been shown to be one of the main sources of patient dissatisfaction with dental care. ${ }^{1}$ Despite this, a survey conducted in 1998 found that there were no formal arrangements at the weekends for as many as $17 \%$ of patients who were not registered with an NHS dentist (5 million) and 66\% (19 million) on weekday evenings. ${ }^{2}$

Numerous reports have been published on models of out-of-hours services for patients with dental problems. ${ }^{3-6}$ Some features appear to have more appeal than others do. For example, it has been suggested that large rotas which reduce the on-call frequency are popular with participating dentists. $^{2}$ Another feature, which reduces the out-of-hours commitment of doctors and dentists, is nurse triage. This is now well established in accident and emergency units $^{7-9}$ and nurse telephone consultations supported by decision support software have been shown to be both safe, effective ${ }^{10}$ and suitable for use in the dental setting. ${ }^{4}$

The population of Fife, located on the east coast of the central belt of Scotland, is in the region of 350,000 . Adult and child registration figures $-51 \%$ and $64 \%$ respec- 
tively - are very similar to those of Scotland as a whole (50\% and 65\%). ${ }^{11}$ Since the majority of dental care in Fife was still predominantly NHS, this meant that almost half of the adult population was unregistered. Until May 2001, outof-hours dental services were provided in a number of different ways and there were no formal arrangements for unregistered patients aside from one weekend day clinic which was very busy. in 2001.

In 2000, a survey of all Fife general dental practitioners indicated that a change towards a more integrated Fife Emergency Dental Service (EDS) would be welcomed and the vast majority ( $>95 \%$ ) in NHS practices agreed to participate in a pilot project. Including Community Dental Service (CDS) clinicians, 115 dentists agreed to participate in the pilot project. Funding was sought from and approved by the Scottish Executive Department of Health to pilot an integrated Fife Emergency Dental Service. The project began on 11 May 2001. This paper evaluates the first year of the pilot.

The pilot project consisted of three main elements: a triage phone line operated by dental nurses following a computer generated algorithm; a rota of GDS practices providing next day appointments on weekdays for unregistered patients; and a weekend emergency dental service (EDS).

The triage line was manned by a rota of nine dental nurses between the hours of $5 \mathrm{pm}$ and $8 \mathrm{am}$ on weekdays, public holidays and all weekend. Experienced dental nurses enrolled to this pilot were given training in the following areas: computer operation, algorithm use, customer care and counselling skills.

The pilot scheme was not given any additional publicity - patients accessed the telephone number through practice answering machines of dentists participating in the pilot project, doctors' out-ofhours schemes and through hospital Accident and Emergency departments. Callers were taken through a computer-generated series of questions - algorithms specifically designed for this pilot project - about the nature of their problem in order to prioritise their care requirements. Figure 1 illustrates one of the series of algorithms.

There were four possible outcomes of calling the triage line, based upon the urgency of the presenting complaint.

1. Where patients were deemed to need true emergency care they were immediately put in contact with Oral and Maxillofacial Surgery (OMFS) staff at the Victoria Hospital in Kirkcaldy.
2. Patients registered with a GDP who had dental problems deemed to require urgent, but not emergency, attention were given appropriate advice and directed to see their GDP the following day.

3. Unregistered patients with problems that were urgent but not emergencies were given appropriate advice and offered access to next day dental appointments through a general dental practice in their area (rota practice).

4. For weekends and main public holidays, patients were triaged to the 'weekend emergency dental service'. This surgery, based at the community dental clinic within the Victoria hospital in Kirkcaldy, was manned on a rota basis by GDS and CDS staff (Saturday 1-4pm, Sunday 10am-1pm). One dentist and two dental nurses manned each session; one nurse in the surgery and the other as receptionist. For each session there was also a second dentist available as standby and to be available in the event of sickness or to deal with domiciliary visits, long stay hospitals, group homes and nursing homes. In the first year of the pilot project, the standby dentist was seldom required.

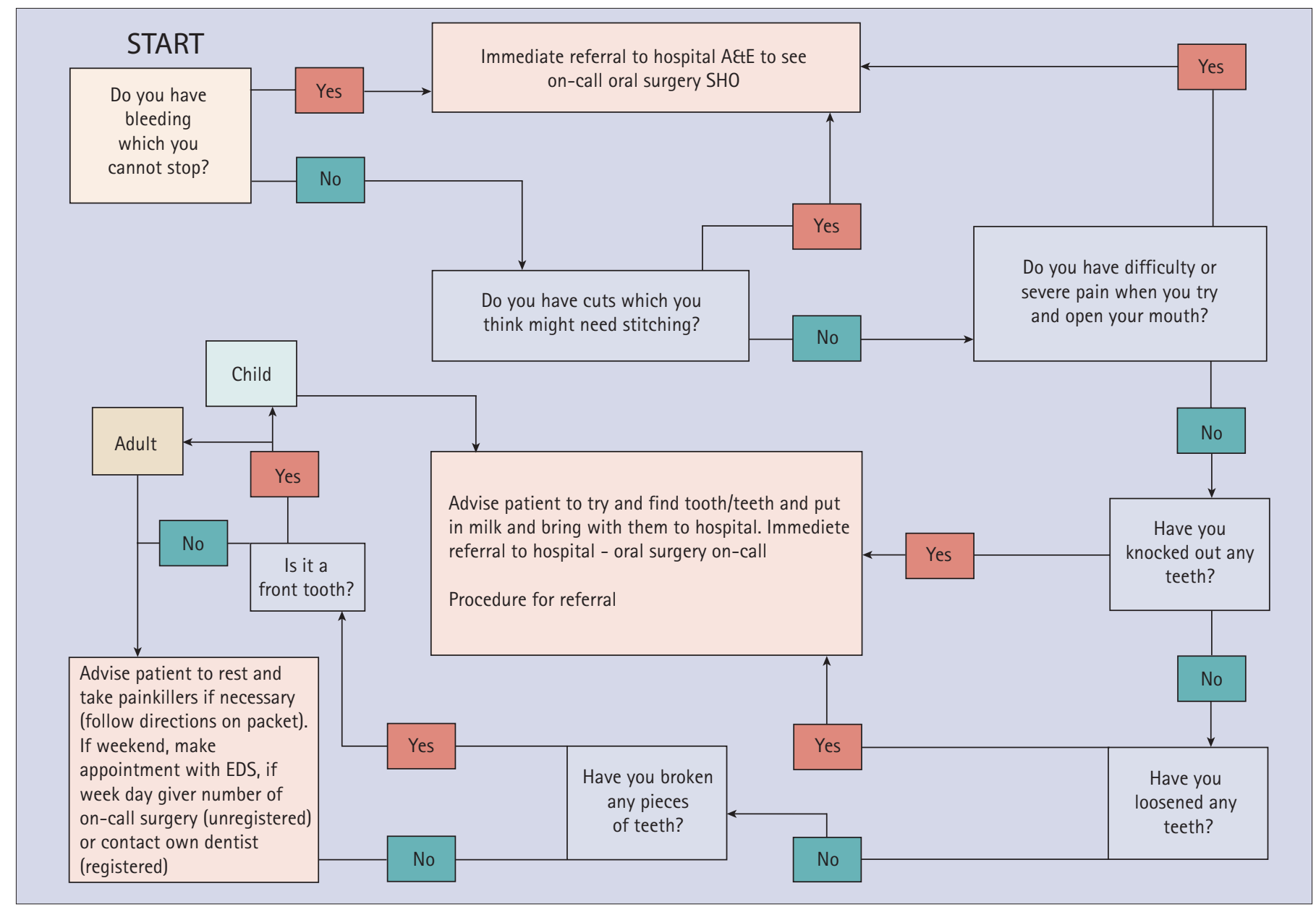


The use of each of these elements of the Fife EDS pilot project was recorded throughout the year, with figures totalled weekly to monitor the activity levels. For simplification, the activity figures are discussed and presented graphically showing totals for thirteen four-weekly periods.

\section{ACTIVITY IN YEAR ONE OF THE PILOT PROJECT (FIG. 2)}

A total of 3,912 calls to the triage line were received over the year, the first four-week period around Christmas and New Year (four-week period 9) was especially busy with 433 calls. Fridays and Saturdays were the busiest evenings for calls to the triage line, as a result $46 \%$ of all callers were subsequently seen at the weekend EDS $(n=1816)$; during the four-week period around Christmas and New Year 176 patients were seen.

Nearly a quarter of the year's total referrals (19/82) for immediate attention from OMFS staff were made in the four weeks of the service as a result of a flaw in the algorithm whereby all callers reporting a swollen face or difficulty in swallowing were triaged for immediate attention, 13 of these being in the first week of the pilot project. The majority of these referrals were unnecessary (14/19); triggered by a fault in the order of questions asked in the algorithm. In consultation with OMFS staff, this was amended in order to triage only those with facial swelling likely to compromise the airway or which affected the ability to swallow. When the algorithm was amended, the number of referrals decreased to an average of between one and two per week.

Throughout the year 479 unregistered patients were referred for a next day appointment with a rota practice and it was of note that only around 50\% of these presented themselves for treatment.

\section{PATIENTS' EXPERIENCES OF ELEMENTS OF THE PILOT PROJECT}

In addition to recording activity throughout the first year of the pilot, four audits were conducted in order to investigate patients' experiences of three elements of the pilot EDS and those of the dentists participating as clinicians at the weekend EDS sessions. Postal questionnaires with a stamped, addressed, return envelope were sent to 200 patients chosen at random from those who had telephoned the triage line for assistance and to all patients $(n=173)$ who had been referred for an appointment with a rota practice over a 16 week period. A reminder was sent one month later to those who had not responded.

To evaluate the weekend emergency dental service, questionnaires were distributed to the first 200 patients attending the service over the two-month period MarchApril 2002. The dentists who saw these patients were also asked to complete questionnaires, principally to identify whether the pilot EDS algorithm was correctly prioritising patients for a weekend appointment.

Taking into account a small number of envelopes returned 'not known at this address', response rates to the postal questionnaires, after one reminder, were $58 \%(114 / 197)$ from triage callers and $41 \%$ (69/169) from those referred to rota practices. Response rates to the questionnaires distributed at the 'weekend EDS' service to patients and dentists were respectively 95\% (190/200) and 97\% (193/200).

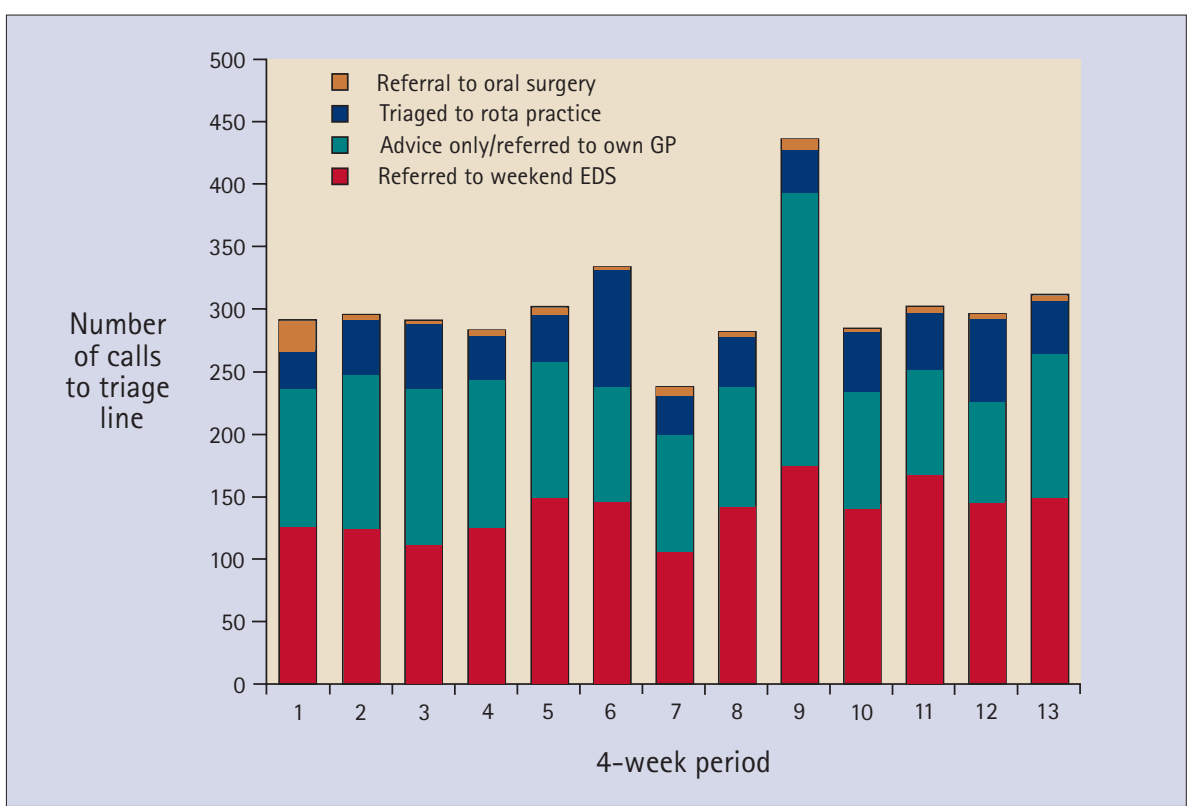

Fig. 2 Out of hours activity in the first year of the pilot project (11 May 2001-10 May 2002)

\section{REGISTRATION STATUS AND ACCESS TO NHS DENTISTRY}

Around one third of the 3,912 individuals who called the triage line in the first year of the pilot stated that they were not registered with a dentist. All of those referred for a rota practice appointment and around $20 \%$ of respondents to the 'weekend EDS' questionnaire reported being unregistered - 3\%, 38\% and 8\% respectively of triage line, rota practice and 'weekend EDS' respondents reported experiencing difficulty in registering with a dentist.

\section{SATISFACTION WITH SERVICE \\ Triage line}

It was found that $90 \%$ of respondents $(n=103)$ were very satisfied with the outcome of their call to the triage line. In addition, almost all respondents - 98\% reported that their call was dealt with in a courteous and polite manner.

\section{ROTA PRACTICE}

Just over one quarter of those respondents that had kept their appointment with a rota dentist $(n=17)$ reported that their dental problem had been resolved. Almost the same proportion $(n=15)$ received satisfactory advice or temporary treatment and were advised to register with a dentist. Around one third of respondents had been given a prescription $(n=24)$, with one in three of these patients also reporting having received temporary treatment.

The majority of comments $(71 \%, n=20)$ were very positive about the attention that had been received. Only three were negative - one patient felt no better for having seen the dentist, one reported having been told there was a one-week wait to be seen and one patient was to have been referred for further attention but had not received an appointment.

\section{'WEEKEND EDS'}

More than $97 \%$ of patients were happy with the advice or treatment that they had received $(n=176)$. Less than 3\% of patients $(\mathrm{n}=5)$ reported any element of dissatisfaction with the service that they had received. Two were dissatisfied with the advice received, even though one stated that their problem had been solved and the other reported having received satisfactory temporary treatment. The remaining three patients were dissatisfied to have been referred to their own GDP for treatment.

\section{DENTISTS' VIEWS OF 'WEEKEND EDS'}

Dentists reported that, in their opinion, the vast majority of the patients $(87 \%, n=168)$ had problems that warranted the urgent appointment that had been provided for them - confirming the validity of the algorithm for this element of the pilot project. 
The most common presenting complaint was 'toothache' $(47 \%, n=90)$ or abscess $(30 \%, n=57)$. Less common presenting complaints included trauma $(n=5)$, loose crown or bridgework $(n=11)$, pericoronitis $(n=3)$, dry socket $(n=15)$ and broken down teeth $(n=8)$. In most cases, the duration of the presenting complaint was less than one week (89\%, $n=171)$. However, a few individuals presented with problems that they had endured for one to two weeks $(n=12)$, two to four weeks $(n=4)$ or one month or more $(n=3)$.

Eighty-five percent $(n=165)$ of patients that the dentists were asked about attended the weekend service with problems associated with bacterial infection (toothache, abscess, pericoronitis and dry socket). The majority (60\%) of these patients were given prescriptions (antibiotics, painkillers, mouthwashes etc) in addition to or instead of local measures. The remaining 40\% were treated using local measures alone.

Dentists reported having referred the majority of these patients for continuing care $(83 \%, n=161)$, almost all of them to general dental practitioners $(98 \%, n=157)$.

\section{DISCUSSION}

\section{Economics of Fife emergency dental services}

Since the pilot project began in May 2001 there was a dramatic reduction in claims from Fife GDPs for attending dental emergencies out of surgery hours (recalled attendances). Figure 3 illustrates the total amount claimed in Fife for recalled attendances in each quarter between 1 April 2000 and 30 June 2002. In the first year of the pilot project, annual recalled attendance claims fell by 74\% from $£ 43,617$ to $£ 11,373$ - a decrease of $£ 32,244$. It should be noted, however, that the number of recalled attendance claims in Fife had fallen slightly prior to the introduction of the pilot. The reason behind this reduction is unclear but it may have been an early indication of growing dissatisfaction among dentists with the previous arrangements.

Table 1 gives a comparison of the costs of each element of the EDS service before

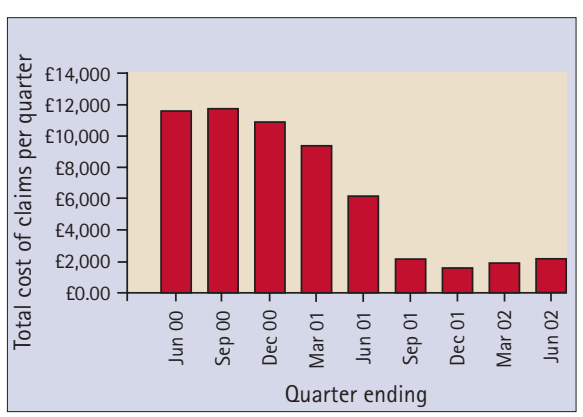

Fig. 3 Recalled attendance claims by Fife GDPs between 1 April 2000 and 30 June 2002 and during the pilot project. Set up costs of around $£ 10,000$ were incurred which are not included in the table.

The total costs of the pilot EDS system of integrated services in Fife appears to have been marginally more than the previous model of emergency/out-of-hours services. However, there has been an increase in the volume of activity and breadth of service and a three fold increase in contacts since the pilot began. For example, there were twice as many weekend sessions in the EDS pilot as there were in the preceding year. The cost per contact seen at the weekend sessions increased, this was because of additional fixed costs, eg standby staff, the annual increase in the rate of payment and travel costs for GDPs (previously these were local dentists - now a number of GDPs come from many surrounding areas).

While appropriately trained non-dental staff could have been considered as a costsaving alternative to using dental nursing staff to manage the triage, it is unlikely that the possible saving of approximately $£ 5,000$ per year in total would outweigh the substantial benefits of having dental experience since there were many queries of a non-urgent dental nature not covered by the algorithms, eg dealing with lost appliances.

Comparing the cost per contact suggests that the EDS pilot is cheaper than the previous model, however these calculations are very simplistic and do not take into account additional elements such the patients seen within the working day by rota practices.

\section{BENEFITS TO PATIENTS}

Whilst- the principal benefit of the Fife pilot EDS model was the improved access for the 190,000 non-registered patients in Fife to out-of-hours dental services, for those patients registered with a dentist, the pilot project represented a trade-off between the variable services previously available and those made available under the terms of the new EDS model. A few individuals who made negative comments on their questionnaires about the triage line $(n=16,14 \%)$ were unhappy that they could not access dental treatment throughout the night. The principal benefits of the pilot EDS model are the guarantees of being able to speak to a real person within 30 minutes at any hour of the night, or at the weekend, for immediate advice and prioritisation of treatment need and a next day appointment seven days per week if deemed necessary.

\section{BENEFITS TO MEDICAL / SPECIALIST DENTAL COLLEAGUES}

It appeared that the pilot project algorithm may have done much to reduce the number of inappropriate contacts with medical colleagues. Around one third of the 3,912 callers to the triage line reported that they did not have a dentist, representing around 1,300 patients per year - who previously often attempted to access care through their doctor or local hospital. Since only 130 callers - 10\% of the unregistered patients - indicated that they had contacted their doctor prior to calling the triage line, this suggests that contacts with medical colleagues may have been reduced by up to $90 \%$ in the first year of the pilot project. This is a simplistic calculation but informal feedback from doctors in Fife suggests that there has been a large reduction in calls from patients experiencing dental problems and doctors are satisfied with the new arrangements. In addition, discussions with OMFS staff confirmed that the vast majority of patients referred to their care were in genuine need of immediate attention and they were content with the accuracy of the EDS algorithm for prioritising patients.

\section{BENEFITS TO DENTISTS}

The annual on-call commitment for each dentist was reduced to only one clinical session and one standby session at the weekend with around four weeks per year commitment as rota dentist. While there was no payment to dentists for their participation in the next day appointment rota, a change to the system of dental remuneration meant that a wider range of treatment could be provided to non-registered patients attracting a better level of remuneration than was previously possible.

Undoubtedly, however, while all participating Fife dentists enjoyed a reduction in

\begin{tabular}{|c|c|c|c|c|c|c|}
\hline & $\begin{array}{l}\text { Number of } \\
\text { contacts }\end{array}$ & $\begin{array}{l}\text { Total } \\
\text { annual cost } \\
€\end{array}$ & $\begin{array}{l}\text { Cost per } \\
\text { contact } \\
€\end{array}$ & $\begin{array}{l}\text { Number of } \\
\text { contacts }\end{array}$ & $\begin{array}{l}\text { Total } \\
\text { annual cost } \\
€\end{array}$ & $\begin{array}{l}\text { Cost per } \\
\text { contact } \\
€\end{array}$ \\
\hline Recalled attendances & 204 & 11,373 & 55.75 & 813 & 43,617 & 53.65 \\
\hline Weekend sessions & 1,816 & 30,000 & 16.52 & 1,022 & 11,389 & 11.14 \\
\hline CDS on-call & - & - & - & 35 & 6,000 & 171.43 \\
\hline Triage line & 3,912 & 28,000 & 7.16 & - & - & - \\
\hline Total & 5,932 & 69,373 & 11.69 & 1870 & 61,006 & 32.62 \\
\hline
\end{tabular}


their out-of-hours commitments, some benefited more than others. In 2001/2, there were a number of 'hot-spots' in Fife where accessing an NHS dentist was more difficult. Practices in these areas, therefore, had a larger pool of unregistered patients and more referrals for next day appointments. While this did not cause dentists to withdraw from the pilot, this issue may become more of a problem as Fife's dental access problem builds.

\section{DIFFICULTIES ENCOUNTERED}

Although the Fife EDS pilot project has been very successful, there were a number of difficulties in the first year of this service. While the out-of-hours commitment of Fife dentists was reduced to one session per year by the introduction of this model of dental care, Community Dental Service nurses were undoubtedly under increased pressure through managing the triage line. An increasing problem in accessing NHS dentistry in Fife has resulted in a rise in the number of calls to the triage line and when the service is particularly busy it is sometimes difficult for the nurses to take a break.

Difficulty in registering with an NHS dentist did not appear to be a problem for most respondents in this study,which was conducted in 2001/02, however, since then there have been recent dramatic increases in the rate of calls to Fife's Primary Care Trust from individuals who are experiencing difficulty in registering for NHS dental care as the national workforce problem worsens. This growing problem of access in Fife as a result of a reduction in the number of NHS sessions provided by local GDPs represents a threat to the EDS model. As the number of patients unable to find an NHS dentist increases the number of calls to the triage line may rise, as well as the demand for next day appointments. It is likely that the EDS model could be modified to cope with this problem. However, this would require the development of a weekday access-type service which could then be linked into the EDS triage algorithms.

\section{CONCLUSIONS}

The first year of the Fife Emergency Dental Service Pilot has proved to be very successful and popular with members of the public, medical and dental professionals alike. The algorithm adopted for this model of care appears to have proved to be an efficient method of managing dental problems out of normal working hours, ensuring that patients receive care within a timeframe that is appropriate to their complaint. It also appears to have reduced the frequency with which non-dental colleagues are contacted by patients with dental problems.

Additional benefits of the project include the improved availability of emergency / out-of-hours dental services, especially for unregistered patients and those who are unable to attend a dental surgery.
The author would like to thank members of the Fife Emergency Dental Service steering group for their assistance in preparing this paper, in particular Ms Dawn Adams, Mr Graham Ball, Mrs Julie Parkinson and Mr Andy Yuill. The author would also like to thank Mr David Evans for his helpful advice.

1. Williams SJ, Calnan M. Convergence and divergence: assessing criteria of consumer satisfaction across general practice, dental and hospital care settings. Soc SciMed 1991; 33: 707-716.

2. Anderson R, Thomas D W. Out-of-hours dental services: a survey of current provision in the United Kingdom. Br Dent J 2000; 188: 269-274.

3. Gibbons D E, West B J. Dentaline: an out of hours emergency dental service in Kent. Br Dent J 1996; 180: 63-66.

4. Evans D J, Smith M P, Grant S M, Crawford M A, Bond J. Out-of-hours emergency dental services development of one possible local solution. Br Dent J 2001; 191: 550-554.

5. Horton M, Harris R V, Ireland R S. The development and use of a triage protocol for patients with dental problems contacting an out-of-hours general medical practitioner co-operative. Prim Dent Care 2001; 8: 93-97.

6. Milsom K M, Zoitopoulos L. Community Dental Service based out of hours emergency dental care - a pilot study. Br Dent J 1993; 174: 177-178.

7. Dale J, Green J, Reid F, Glucksman F. Primary care in the accident and emergency department. I:

Prospective identification of patients. Br Med J 1995: 311: 423-6.

8. Dale J, Green J, Reid F, Glucksman F. Primary care in the accident and emergency department. II: Comparison of general practitioners and hospital doctors. BrMed J 1995; 312: 1340-1344.

9. Green J, Dale J. Primary care in the accident and emergency and general practice; a comparison. Soc SciMed 1992; 35: 987-995.

10. South Wiltshire Out-of-hours Project (SWOOP) Group. Nurse telephone triage in out-of-hours primary care: a pilot study. BrMed J 1997; 314: 198-9.

11. Scottish Dental Practice Board. Annual report 2000/01. Edinburgh, 2001. 